\title{
Changes in organic carbon fractions and sources in deltaic topsoil and subsoil layers: autochthonous and allochthonous inputs
}

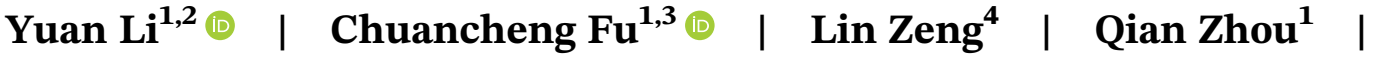 \\ Haibo Zhang ${ }^{5}$ | Chen $\mathrm{Tu}^{1,2}$ | Lianzhen $\mathrm{Li}^{1,2}$ | Yongming Luo ${ }^{1,2,3}($ ) \\ ${ }^{1}$ CAS Key Laboratory of Coastal Environmental Processes and Ecological Remediation, Yantai Institute of Coastal Zone Research (YIC), Chinese \\ Academy of Sciences (CAS); Shandong Key Laboratory of Coastal Environmental Processes, YICCAS, Yantai, China \\ ${ }^{2}$ Center for Ocean Mega-Science, Chinese Academy of Sciences, Qingdao, China \\ ${ }^{3}$ CAS Key Laboratory of Soil Environment and Pollution Remediation, Institute of Soil Science, Chinese Academy of Sciences (CAS), Nanjing, China \\ ${ }^{4}$ School of Resources and Environmental Engineering, Ludong University, Yantai, China \\ ${ }^{5}$ Key Laboratory of Soil Contamination Bioremediation of Zhejiang Province, School of Environmental and Resource Sciences, Zhejiang Agriculture \\ and Forestry University, Hangzhou, China
}

\section{Correspondence}

Yongming Luo, CAS Key Laboratory of

Soil Environment and Pollution

Remediation, Institute of Soil Science,

Chinese Academy of Sciences (CAS)

Nanjing 210008, China.

Email: ymluo@issas.ac.cn

\section{Funding information}

National Natural Science Foundation of China, Grant/Award Numbers: 41701263 ,

42007022, 41991330, 41807418

\section{Abstract}

River deltas are often considered as hotspots of atmospheric carbon regulation, but few studies have paid attention to the differences between topsoil and subsoil for carbon sequestration. Here physical and chemical stabilization mechanisms and sources of soil organic carbon (OC) accumulation in different soil layers of a major river delta (Yellow River delta) were studied by fractionation and isotopic analysis. We found that in topsoil, conversion from tidal flat to wetland substantially increases OC by $84 \%$, whereas cotton cultivation decreases OC by $66 \%$. Wetland with a high soil OC content is characterized by substantial accumulation of plant-derived OC and OC in mineral fractions. In subsoil, the OC variation is controlled by the yellow silt layer (YSL)-red clay layer (RCL) sequence. Although the weathering intensity of the RCL is much higher than that of the YSL, the OC age is younger in the RCL, indicating that the highly reactive, secondary minerals and iron oxides are capable of stabilizing younger organic carbon in transportation, deposition and post-pedogenic alteration. ${ }^{14} \mathrm{C}$ activity demonstrates that modern autochthonous $\mathrm{OC}$ is the main component of $\mathrm{OC}$ in wetland topsoil. In contrast, millennia-old allochthonous $\mathrm{OC}$ is the main component of $\mathrm{OC}$ in the subsoil layers, contributing $4-24 \%$ of total bulk soil OC. The higher $\delta^{13} \mathrm{C}$ values of carbon fractions $(-24.3$ to $-21.4 \%$ for the intra-aggregate particulate organic matter fraction, intramicroaggregate silt and clay fraction, and free silt and clay faction) and bulk samples $(\sim-22 \%)$ are likely to imply the contribution of aged OC in the Yellow River delta. This study offers direct confirmation that soil OC fractions and sources are influenced by different land-use types and pedological properties in characteristic soil layers. These findings suggest that biogeochemical alteration 
of the soil matrix controls OC stabilization mechanisms in the river sedimenttidal flat-wetland-farmland continuum.

\section{Highlights}

- Land-use types and pedological features control OC storage in topsoil and subsoil, respectively.

- Reclamation strongly decreases content of all OC fractions and the proportion of fSC and rOC.

- Soil layers with distinct texture and mineral compositions lead to OC stratification in subsoil.

- The red clay layer in subsoil is capable of stabilizing both fresh and aged OC.

\section{KE Y W O R D S}

organic carbon fractionation, organic carbon stabilization, radiocarbon, river delta, soil organic matter, subsoil

\section{1 | INTRODUCTION}

River deltas are hotspots of organic carbon (OC) deposition, burial and transformation, being important in the context of global C cycling (Bianchi \& Allison, 2009). River deltas bury $75 \times 10^{12} \mathrm{~g}$ of OC annually due to their high sediment loads, which is responsible for $41 \%$ of OC buried along continental margins (Bianchi \& Allison, 2009; Smith, Bianchi, Allison, Savage, \& Galy, 2015). On deltaic topsets, blue carbon ecosystems (salt-marsh, mangrove and seagrass) that develop on wetlands are remarkably efficient at accumulating OC, with accumulation rates (e.g., $218 \pm 24 \mathrm{~g} \mathrm{C} \mathrm{m}^{-2}$ year $^{-1}$ ) as much as 50 times greater than those of boreal, tropical and temperate forests $\left(\sim 4-5 \mathrm{~g} \mathrm{C} \mathrm{m}^{-2}\right.$ year $\left.^{-1}\right)$ (McLeod et al., 2011). However, human disturbances and climate change, including land-use change, eutrophication, sea-level rise and warming, have threatened deltaic OC storage and sink capacity (Day et al., 2016; Schuerch et al., 2018). Understanding OC transformation and the preservation process of newly deposited and ancient OC is therefore key to the sustainability of deltaic ecosystems (Day et al., 2016; Shields et al., 2017; Spivak, Sanderman, Bowen, Canuel, \& Hopkinson, 2019).

In newly formed river deltas, soil layers are generally developed by periodic deposition of river sediments. These sediments transfer different sources of riverine OC, which can simply be considered as ancient fossil OC and biospheric OC derived from modern biomass (Bouchez et al., 2014; Xue, Zou, Ge, \& Wang, 2017). These OC components are sequestered in a wide range of particle sizes and densities and thereby are susceptible to partial separation via hydrodynamic sorting that results in OC stratification with depth at the land-ocean interface (Bianchi et al., 2018; Galy et al., 2007). It has been well documented that OC buried in river deltas and estuaries can be partially stabilized against decomposition within aggregates of allochthonous mineral-associated particles (Bianchi et al., 2018; Spivak et al., 2019). Although OC buried in the delta is tightly linked to the accumulated sediments, vegetation succession also enhances the autochthonous OC inputs from plant production (Shields et al., 2017). This suggests that mineral association plays an essential role in preservation of OC in subsoil, whereas its importance becomes marginal when autochthonous $\mathrm{OC}$ is increasingly incorporated into topsoil (Chabbi, Kögel-Knabner, \& Rumpel, 2009; Matteodo et al., 2018; Salomé, Nunan, Pouteau, Lerch, \& Chenu, 2010; Van de Broek et al., 2018). Historically, most of the studies on soil OM stabilization mechanisms have focused on the topsoil (Rumpel \& Kögel-Knabner, 2011). However, there is growing recognition that the contributions of subsoil OC have been vastly underestimated and the factors controlling OC dynamics in subsoil have been largely ignored (Schmidt et al., 2011; Sokol \& Bradford, 2019). Most subsoil layers with low OC concentrations may not yet be saturated in OC. They have the potential to sequester labile dissolved OC compounds from aboveground inputs as well as microbial products from belowground inputs (Rumpel \& KögelKnabner, 2011; Sokol \& Bradford, 2019).

The Yellow River delta is one of a few prograding deltas as a result of high sediment loads of the Yellow River, which was once ranked the most turbid river in the world, delivering $1 \times 10^{9}$ t year $^{-1}$ sediment to the sea (Milliman \& Syvitski, 1992). The Yellow River delta has the largest and youngest wetland ecosystem in China, being an important overwintering and breeding site for many rare and endangered migrating birds. Meanwhile, the Yellow River delta has been undergoing extensive 
and rapid development of agriculture over recent decades and a large portion of wetlands has been converted to farmland (Li et al., 2016; Yu et al., 2016). In our previous studies, we found that wetland topsoil OC with low $\delta^{13} \mathrm{C}$ and $\delta^{15} \mathrm{~N}$ values was acting as a labile OC pool in the Yellow River delta (Li et al., 2016). In subsoil, a red clay layer 5-50 cm thick and $1 \mathrm{~m}$ deep in the soil profile was widely distributed in the Yellow River delta. The formation of the red clay layer is related to hydrodynamic sorting and it is likely to be derived from the loesspaleosol-red clay sequence of the Chinese Loess Plateau (Li et al., 2019). Globally, a large amount of these loesspaleosol-red clay materials is delivered to the coastal seas by river systems (Li, Shi, Aydin, Beroya-Eitner, \& Gao, 2020). At present, studies on the geochemical implications of soil layers in river estuaries that developed from loess-like deposits are still lacking. A suite of recent studies have found that carbon accumulation in the Yellow River delta is related to soil texture, minerals, salinity and moisture along soil profiles (Li et al., 2020; Yin et al., 2019; Zhao et al., 2018). Hence, it is imperative to elucidate the underlying mechanisms for soil OC sequestration and predict soil OC stock changes as a function of management and environmental drivers. Recent frameworks suggest that soil OC accrual, persistence and response to disturbance can be better described if soil OC is broadly divided into physically based and chemically based fractions (Cotrufo, Ranalli, Haddix, Six, \& Lugato, 2019; Cui et al., 2014; Doetterl et al., 2018). We hypothesize that soil OC sequestration potentials in both topsoil and subsoil, considering characteristic layers under different land-use types in river deltas receiving loess-like deposits, can be better understood through a framework based on the fractionation and source identification of soil OC.

In this study, we applied physical and chemical fractionation combined with ${ }^{14} \mathrm{C}$ and ${ }^{13} \mathrm{C}$ measurements to understand (a) how OC stabilization mechanisms vary in the river sediment-tidal flat-wetland-farmland continuum and (b) whether the underlying processes of OC stabilization and $\mathrm{OC}$ sources are different in soil layers.

\section{MATERIALS AND METHODS}

\section{1 | Site description}

As one of three major river deltas in China, the modern Yellow River delta (Region 1, Figure 1a), with an area of more than $6,000 \mathrm{~km}^{2}$, has formed since 1855 , when the Yellow River shifted its course to the Bohai Sea. Rapid deposition of the suspended sediment has shifted the deltaic river channel a total of 11 times, resulting in the formation of different sedimentary successions. The sedimentary successions in the Yellow River delta are characterized by cyclic changes of clay-enriched layers and silt-enriched layers, which are likely to be due to hydrodynamic sorting, provenance change and postdepositional alteration (Li et al., 2019; Saito et al., 2000; Xue, Zhu, \& Lin, 1995). The particulate OC transported by the Yellow River is enriched in fine fractions of sediments (Qu et al., 2020). Biomass OC derived from C3 plants contributed $52-65 \%$ in the Yellow River basin and lower reach, whereas pre-aged soil OC contributed 60 (a)

a)

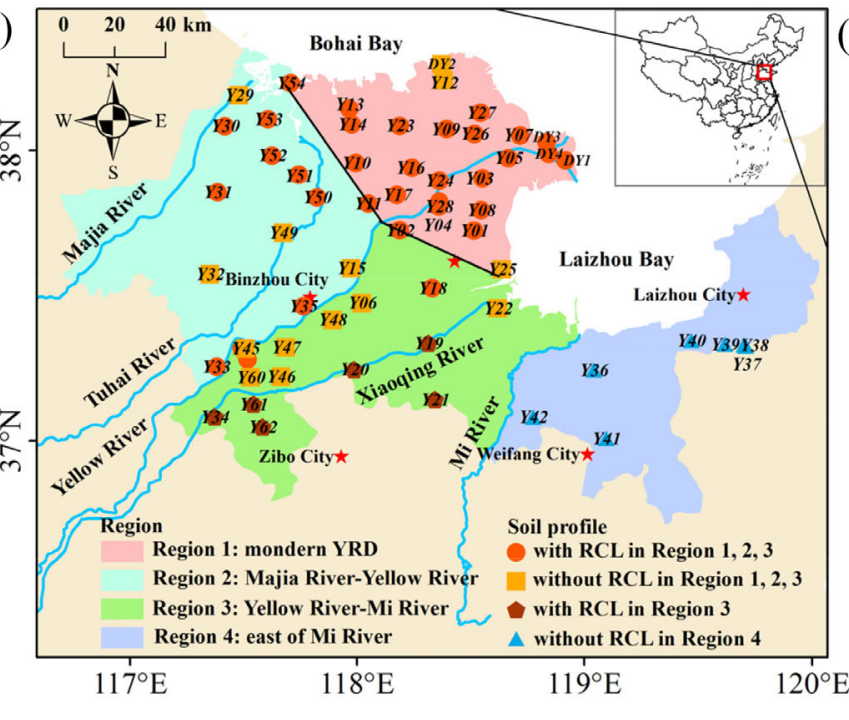

(b)

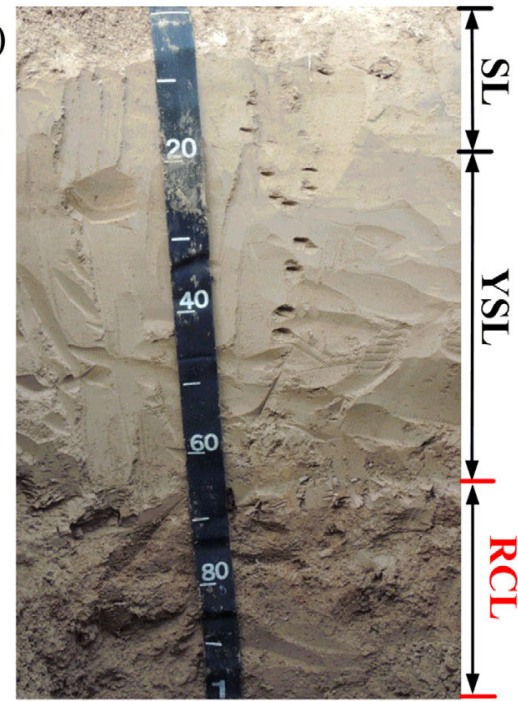

F I G U RE 1 (a) Map showing the sampling sites and the spatial distribution of the red clay layer (RCL) in the Yellow River delta; (b) a typical soil profile showing the vertical distribution of the surface layer (SL), yellow silt layer (YSL) and red clay layer (RCL) [Color figure can be viewed at wileyonlinelibrary.com] 
$70 \%$ of riverine particulate OC (Xue et al., 2017). The modern Yellow River delta (Region 1, Figure 1a) is the core area of the Yellow River delta High-Efficiency EcoEconomic Zone (Region 1-4, Figure 1a) and is the dominant red clay-yellow silt layer sequence distribution area, with $91 \%$ of the sampled soil profiles occurring in the red clay layer. The OC storage in the topsoil layer is sensitive to land-use change (Li et al., 2016), whereas the element compositions in subsoil layers are largely controlled by the red clay-yellow silt layer sequence, with distinct weathering degree, mineralogy and grain size (Li et al., 2019).

The average annual precipitation in the modern Yellow River delta is $560 \mathrm{~mm}$, and about $\mathbf{7 4 \%}$ is concentrated in the period June to September. Average evaporation is $1,900-2,400 \mathrm{~mm}$. The hydrological characteristics in the modern Yellow River delta are affected by the interactions between freshwater and seawater and between groundwater and surface water due to the low elevation (generally below $10 \mathrm{~m}$ ) and being near the sea (Han et al., 2015; Zhao et al., 2018). The average depth of the groundwater table in this region is less than $1.5 \mathrm{~m}$ and total dissolved solids exceed $15 \mathrm{~g} \mathrm{~L}^{-1}$ (Fan et al., 2012). Therefore, saline and wet soils are found in extensive areas in the modern Yellow River delta. Soil types in the modern Yellow River delta are dominated by Gleyic Solonchaks, Salic Fluvisols and Calcaric Fluvisols (Li et al., 2016). The land-use types in the modern Yellow River delta are dominated by farmland (cotton is the dominant crop because of its high soil salinity tolerance), wetland and tidal flat, accounting for $32.8,30.3$ and $18.9 \%$ of the total area, respectively (Yu et al., 2016). Dominant plant species in the wetland primarily comprise Phragmites australis, Suaeda heteroptera and Tamarix chinensis.

\section{2 | Soil sampling}

In our previous study, a total of 42 soil profiles (Y01-Y42) and 15 cores (Y45-Y54, Y58-Y62) were collected in the Yellow River delta for red clay layer identification (Figure 1a) (Li et al., 2019). All soil samples were collected using a stainless-steel hand auger and then placed into polyethylene bags. Soil profiles were sampled according to diagnostic layers until a depth of $1 \mathrm{~m}$. The red clay layer typically has a median grain size of $<20 \mu \mathrm{m}$, redness $\left(\mathrm{a}^{*}\right)$ of $>7$ and frequency-dependent susceptibility $\left(\chi_{\mathrm{fd}} \%\right)$ of $>6 \%$ ( $\mathrm{Li}$ et al., 2019; Li, Zhang, Tu, \& Luo, 2018). Accordingly, soil profiles could be characterized by three soil layers: the surface layer, red clay layer and yellow silt layer (Figure 1b) (Li et al., 2019). The values of median grain size, $\mathrm{a}^{*}$ and $\chi_{\mathrm{fd}} \%$ of soil profiles occurring in the red clay layer among the 42 soil profiles are shown in Table S1. To calculate the mass accumulation rate, a high-resolution soil profile (Y23) occurring in the red clay layer was sampled at an interval of $5 \mathrm{~cm}$ in the $120-\mathrm{cm}$ depth with 24 soil layer samples from the groundwater table to the surface. The Yellow River bed sediments at the estuary and soil profiles from tidal flat as additional samples were collected (DY1-DY4). Soil profiles from the tidal flat (DY1, DY3, DY4), wetland (Y05, Y07, Y12, Y23) and farmland (cotton field) (Y04, Y08, Y14, Y16), together with the Yellow River bed sediment in the modern Yellow River delta, were selected for investigating carbon changes in different soil diagnostic layers. For the Yellow River bed sediment, we took mixed samples from three sites (500 m apart) to the depth of $20 \mathrm{~cm}$ along the river. The classification of soil layers is shown in Table S2. Soil profiles used for analysis (Table S2) were located in the modern Yellow River delta (Region 1, Figure 1a), which has experienced rapid and extensive agricultural reclamation over the past decades. Meanwhile, all these soil profiles have a typical red clay layer, as indicated by the values of median grain size, $\mathrm{a}^{*}$ and $\chi_{\mathrm{fd}} \%$ (Table 1 ).

\section{3 | Carbon fractionation}

Physical protection (physical isolation of OC within aggregates) and chemical stabilization (chemical or physicochemical binding of OC to soil minerals) are two main mechanisms of OC stabilization (Kaiser \& Guggenberger, 2003; Stewart, Plante, Paustian, Conant, \& Six, 2008). The surface layer, red clay layer and yellow silt layer in soil profiles were used for physical and chemical fractionation. Representative soil layer samples used for carbon fractionation are shown in Table S2. The fractionation schemes are shown in Figure 2. The interpretation in terms of functional $\mathrm{C}$ pools and protection mechanisms is provided in Table S3.

Physical fractionation followed a procedure proposed by Stewart et al. (2008) with only minor modifications to mainly separate particulate organic matter (POM) into coarse particulate organic matter $(>250 \mu \mathrm{m})$, microaggregate-associated organic matter $(250-53 \mu \mathrm{m})$ and non-aggregated silt and clay organic matter $(<53 \mu \mathrm{m})$ (Figure 2a). The fractionation began with 2-mm-sieved soil because the soil texture in the Yellow River delta was dominated by silt, sandy silt and clayey silt, with very few particles over $2 \mathrm{~mm}$. Briefly, 2-mm-sieved soil was rapidly immersed in deionized water for $5 \mathrm{~min}$ for soil slaking, then placed in a soil aggregate analyzer (TTF-100, Shunlong Experiment Instrument Factory, China) to pass over a $250-\mu \mathrm{m}$ and $53-\mu \mathrm{m}$ sieve, yielding a sand fraction and macroaggregate fraction larger than $250 \mu \mathrm{m}$, together with coarse particulate organic matter (cPOM), a free 


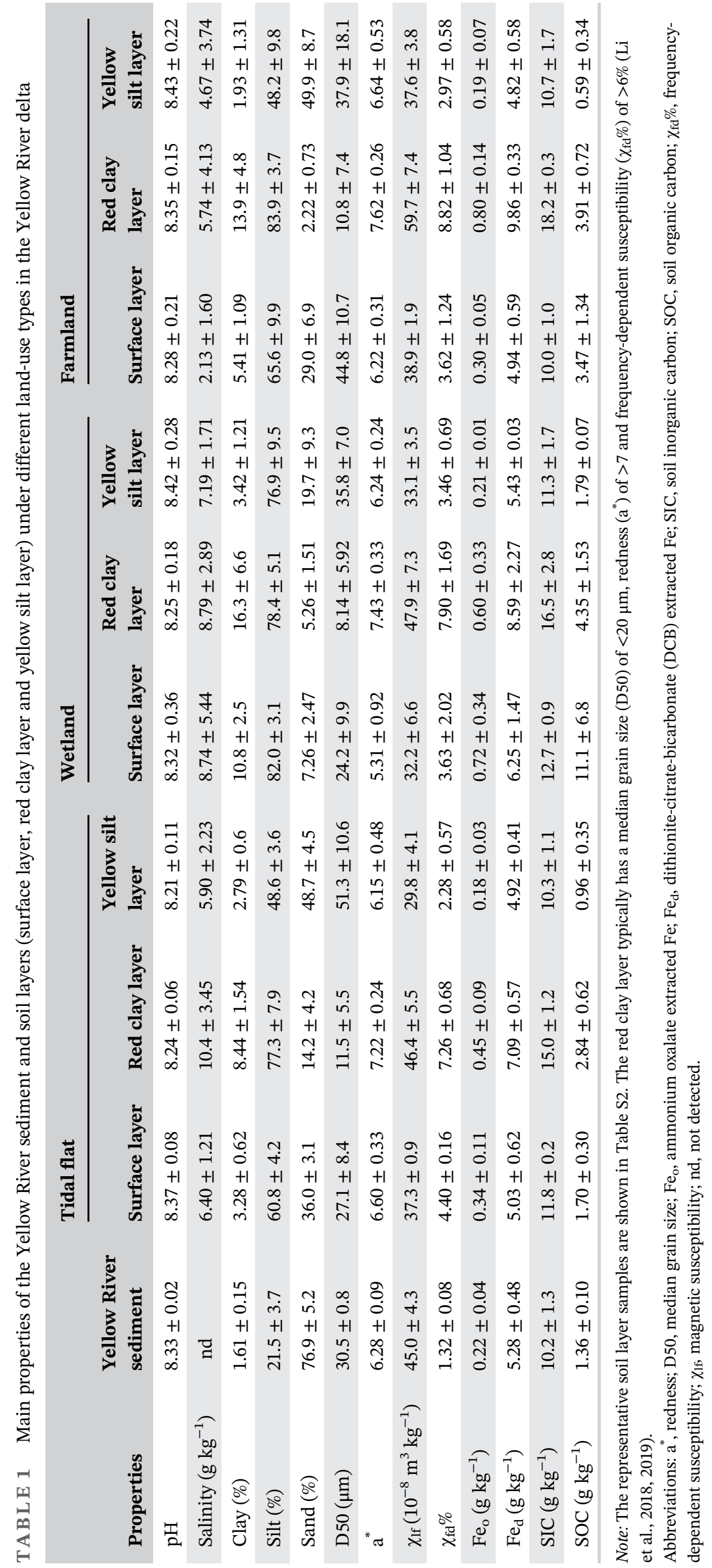




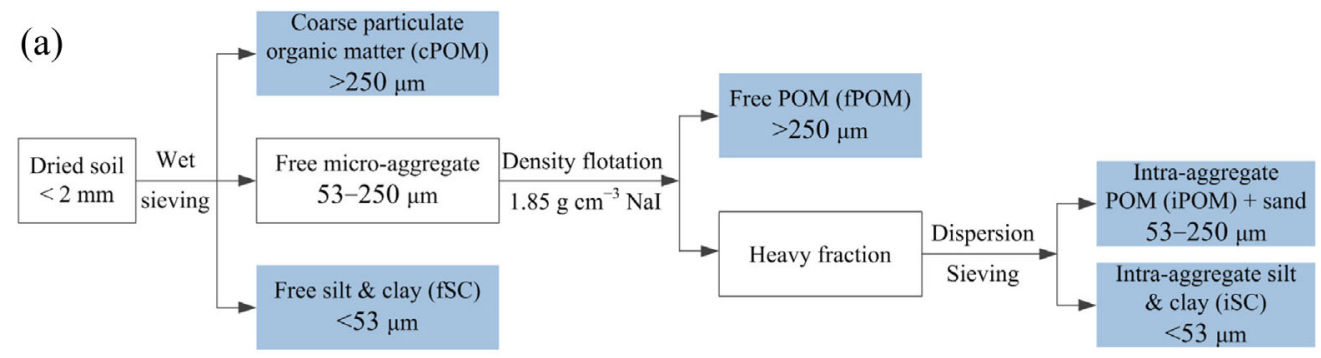

FIGURE 2 Simplified diagrams of (a) physical fractionation and (b) the chemical fractionation procedure, with final derived fractions highlighted in blue [Color figure can be viewed at wileyonlinelibrary.com]

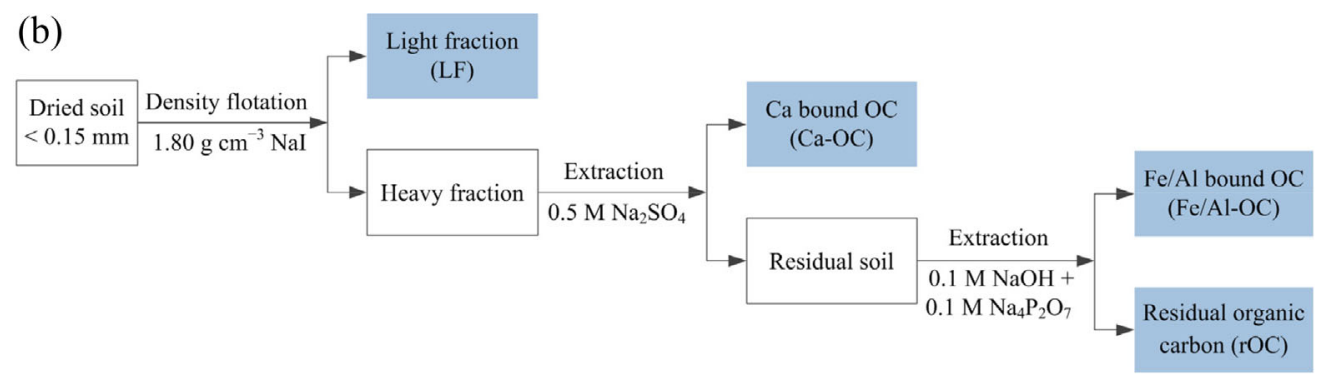

microaggregate fraction between 250 and $53 \mu \mathrm{m}$ and free silt \& clay faction (fSC) smaller than $53 \mu \mathrm{m}$. Afterwards, the free microaggregate fraction was subjected to density flotation in $1.85 \mathrm{~g} \mathrm{~cm}^{-3} \mathrm{NaI}$ for separation of free POM (fPOM). The remaining heavy fraction was dispersed by $0.5 \%$ sodium hexametaphosphate for $18 \mathrm{~h}$. The dispersed heavy fraction was passed through a $53-\mu \mathrm{m}$ sieve and the intra-aggregate particulate organic matter (iPOM) fraction (together with sand) remained on the sieve. The passed suspension was centrifuged at $3000 \mathrm{~g}$ to collect the intramicroaggregate silt \& clay (iSC) fraction. All POM fractions were freeze-dried and weighed. The recovery of the fractionation ranged from 89.3 to $94.4 \%$.

Chemical fractionation followed a procedure proposed by Xu and Yuan (1993) to separate the mineralbound $\mathrm{OC}$ into $\mathrm{OC}$ bound to calcium $(\mathrm{Ca}-\mathrm{OC}), \mathrm{Fe} / \mathrm{Al}$ oxyhydrates (Fe/Al-OC) and residual soil minerals (rOC) (Figure $2 \mathrm{~b}$ ). The method has been successfully used for separation of $\mathrm{Ca}$ bound organic carbon $(\mathrm{Ca}-\mathrm{OC})$ and iron/aluminium bound organic carbon $(\mathrm{Fe} / \mathrm{Al}-\mathrm{OC})$ in the Yangtze River delta (Cui et al., 2014). Samples for chemical fractionation were ground to pass a $0.15-\mathrm{mm}$ sieve to enhance extraction efficiency and to get a better result. Briefly, 0.15-mm-sieved soil was firstly subjected to density flotation in $1.80 \mathrm{~g} \mathrm{~cm}^{-3} \mathrm{NaI}$ to separate the free light fraction (LF) (i.e., the floating materials). The heavy fraction was obtained after washing two times with deionized water and then extracted by shaking for $1 \mathrm{~h}$ with $0.5 \mathrm{M} \mathrm{Na}_{2} \mathrm{SO}_{4}$, allowed to stand overnight and then centrifuged to obtain the $\mathrm{Ca}-\mathrm{OC}$. The procedure above was repeated in triplicate and the supernatants were combined. After being washed with distilled water, the residue was subsequently extracted by $0.1 \mathrm{M} \mathrm{NaOH}+0.1 \mathrm{M}$ $\mathrm{Na}_{4} \mathrm{P}_{2} \mathrm{O}_{7}$ to obtain the $\mathrm{Fe} / \mathrm{Al}-\mathrm{OC}$ using the same procedure above. Finally, the residual soil fraction was obtained and referred to as residual organic carbon (rOC).

\section{4 | Soil analysis}

Soil samples were air-dried and passed through a 2-mm sieve for determination of $\mathrm{pH}$, salinity, soil particle size and ${ }^{210} \mathrm{~Pb}$ activity. A quarter of the sieved fraction was subsequently crushed to pass a $0.149-\mathrm{mm}$ sieve for measurement of $\mathrm{C}$ content, isotopic value, magnetic property and redness.

Soil $\mathrm{pH}$ and salinity were measured using 1:2.5 and 1:5 soil:water mixtures, respectively. Soil grain size was measured using a Malvern Mastersizer 2000 instrument after removing organic matter and carbonates using $15 \% \mathrm{H}_{2} \mathrm{O}_{2}$ and $1 \mathrm{M} \mathrm{HCl}$, and then dispersed in $0.05 \mathrm{M}$ sodium hexametaphosphate solution overnight, followed by ultrasonic treatment at an energy output rate of $170 \mathrm{~J} \mathrm{~min}^{-1}$ for $30 \mathrm{~min}$.

Determination of ${ }^{210} \mathrm{~Pb}$ activities of the highresolution soil profile (Y23) samples was conducted using an EG \& G Ortec HPGe GWL gamma-ray spectrometer (Ametek Inc., Berwyn, PA). The total ${ }^{210} \mathrm{~Pb}$ and ${ }^{226} \mathrm{Ra}$ activities were measured at $46.5 \mathrm{keV}$ and $295.2 \mathrm{keV}$ $\left({ }^{214} \mathrm{~Pb}\right)$, respectively. Excess ${ }^{210} \mathrm{~Pb}\left({ }^{210} \mathrm{~Pb}_{\mathrm{ex}}\right)$ was calculated by subtracting ${ }^{226} \mathrm{Ra}$ activity from total ${ }^{210} \mathrm{~Pb}$ activity. The Constant Rate of Supply (CRS) model (Text S1) was used for the determination of mass accumulation rate (MAR) (Arias-Ortiz et al., 2018). 
Free iron oxides $\left(\mathrm{Fe}_{\mathrm{d}}\right)$ were extracted by the dithionite-citrate-bicarbonate (DCB) method. Soil samples were added to a solution containing a buffer (sodium bicarbonate, $\mathrm{pH}$ 7.3) and a metal ion complexing agent (trisodium citrate) in capped centrifuge tubes and heated to $80^{\circ} \mathrm{C}$ in a water bath. A reducing agent (sodium dithionite) was added to the mixture and maintained at $80^{\circ} \mathrm{C}$ for $15 \mathrm{~min}$. The poorly crystalline iron oxides $\left(\mathrm{Fe}_{\mathrm{o}}\right)$ were extracted by $0.2 \mathrm{M}$ acid ammonium oxalate at $\mathrm{pH} 3.0$ in the darkness for $4 \mathrm{~h}$ in a mechanical shaker. Following the extraction treatments, the supernatant was separated from the solid fraction by centrifugation at $3000 \mathrm{~g}$ for $10 \mathrm{~min}$. The extracted Fe was determined at $512 \mathrm{~nm}$ by UV/Vis spectrophotometric detection using 1,10-phenanthroline as complexing agent.

Soil magnetic susceptibility was measured at low $(0.47 \mathrm{kHz})$ and high $(4.7 \mathrm{kHz})$ frequency $\left(\chi_{\mathrm{lf}}\right.$ and $\chi_{\mathrm{hf}}$, respectively) using a Bartington MS2 susceptibility meter and MS2B dual-frequency sensor. Frequency-dependent susceptibility $\left(\chi_{\mathrm{fd}} \%\right)$ was calculated as $\chi_{\mathrm{fd}} \%=\left(\chi_{\mathrm{lf}}-\chi_{\mathrm{hf}}\right) /$ $\chi_{\mathrm{lf}} \times 100$. Magnetic susceptibility $\left(\chi_{\mathrm{lf}}\right)$ generally reflects the concentration of magnetic minerals. $\chi_{\mathrm{fd}} \%$ is sensitive only to fine, viscous superparamagnetic (SP)/single domain (SD) ( 20-25 nm for maghemite) grains (Liu et al., 2012). Higher values of $\chi_{\mathrm{lf}}$ and $\chi_{\mathrm{fd}} \%$ indicated higher degree of weathering in the YRD soil, which was extremely useful in identifying the characteristic soil layer (Li et al., 2018).

For redness measurement, soil samples were placed in special small glass channels and pressed into a flat surface using a smooth glass slide. The soil flat surface was illuminated with a colorimeter (CR-10, Konica Minolta, Tokyo, Japan) to obtain the colour parameters a ${ }^{*}$ (redness).

Total carbon, OC of bulk soil and different carbon fractions obtained by physical fractionation (cPOM, fSC, fPOM, iPOM and iSC) and LF and rOC fractions obtained by chemical fractionation were measured on a Vario MACRO cube elemental analyzer (Elementar, Germany). For OC measurement, soil samples (about $0.5 \mathrm{~g}$ ) were acidified to $\mathrm{pH}=1-2$ with $1 \mathrm{M} \mathrm{HCl}(20 \mathrm{~mL})$ for $16 \mathrm{~h}$ to remove carbonates and then weighed and subsequently rinsed with deionized water to wash and neutralize. Soil inorganic carbon (SIC) was calculated as the difference between total carbon and OC. The extracted $\mathrm{Ca}-\mathrm{OC}$ and $\mathrm{Fe} / \mathrm{Al}-\mathrm{OC}$ were measured with a TOC-VCPH Total Organic Carbon Analyzer (Shimadzu, Japan). Quality assurance and quality control were assessed using duplicates and standard reference materials (GSS-1 and GSS-8) from the National Reference Center for Certified Reference Materials of China with $10 \%$ of the samples. The recoveries for the carbon in the standards ranged from 95.7 to $102.1 \%$.
Stable organic carbon isotope $\left(\delta^{13} \mathrm{C}\right)$ measurements were made with decarbonated samples for $\mathrm{OC}$ content analysis (after $1 \mathrm{M} \mathrm{HCl}$ treatment) using an elemental analyser (Flash EA 1112, Thermo Finnigan) interfaced with an isotope ratio mass spectrometer (MAT 253, Thermo Finnigan) operating in continuous flow mode. $\delta^{13} \mathrm{C}$ was expressed as relative to the international standard of pee dee belemnite. Replication had a standard deviation better than $\pm 0.1 \%$ o based on the repeated measurements of the international standard IAEA- 600 . Reproducibility of sample replicates was generally better than $\pm 0.2 \%$ or $\delta^{13} \mathrm{C}$.

The surface layer, red clay layer and yellow silt layer from one typical soil profile of tidal flat, wetland and farmland, together with the Yellow River sediment, were

(a)

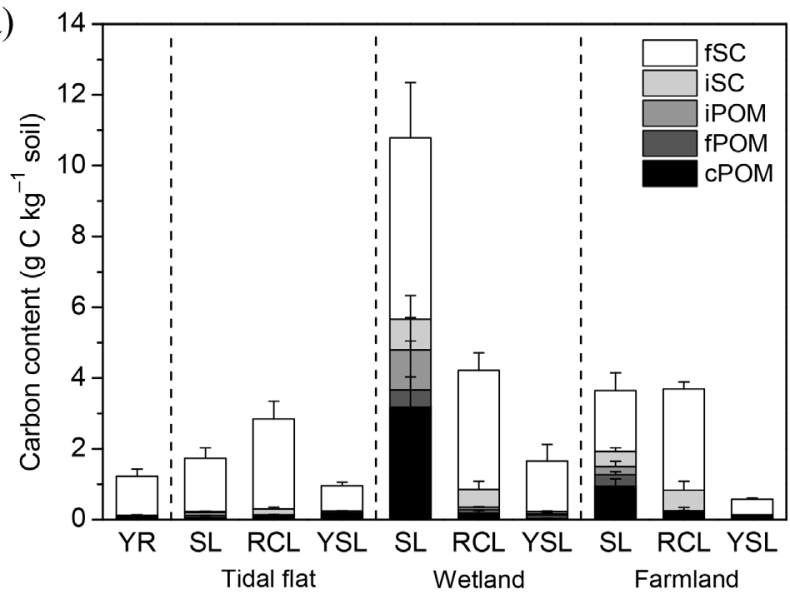

(b)

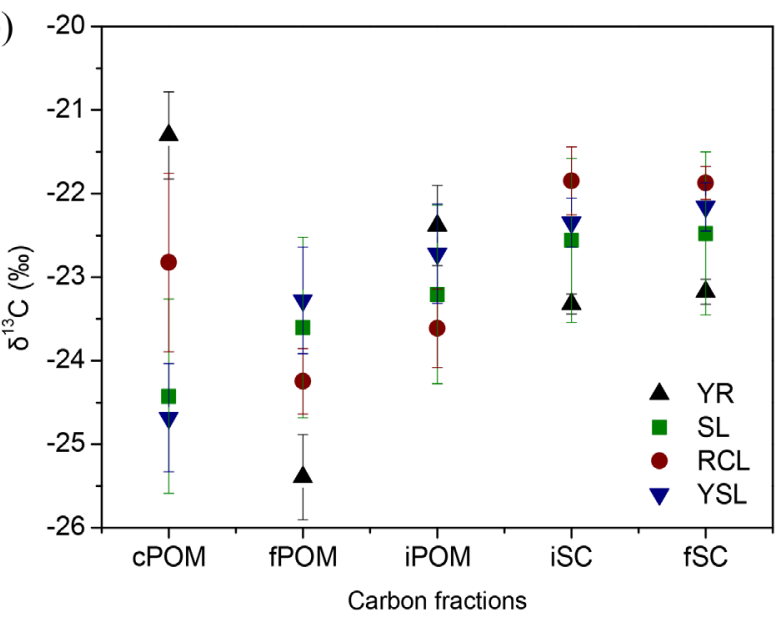

F I G URE 3 Carbon fractions obtained by physical fractionation in the Yellow River sediment (YR) and different soil layers (SL, surface layer; RCL, red clay layer; YSL, yellow silt layer).

(a) Showing carbon fraction contents in different land use types, (b) showing carbon fraction isotopic compositions [Color figure can be viewed at wileyonlinelibrary.com] 

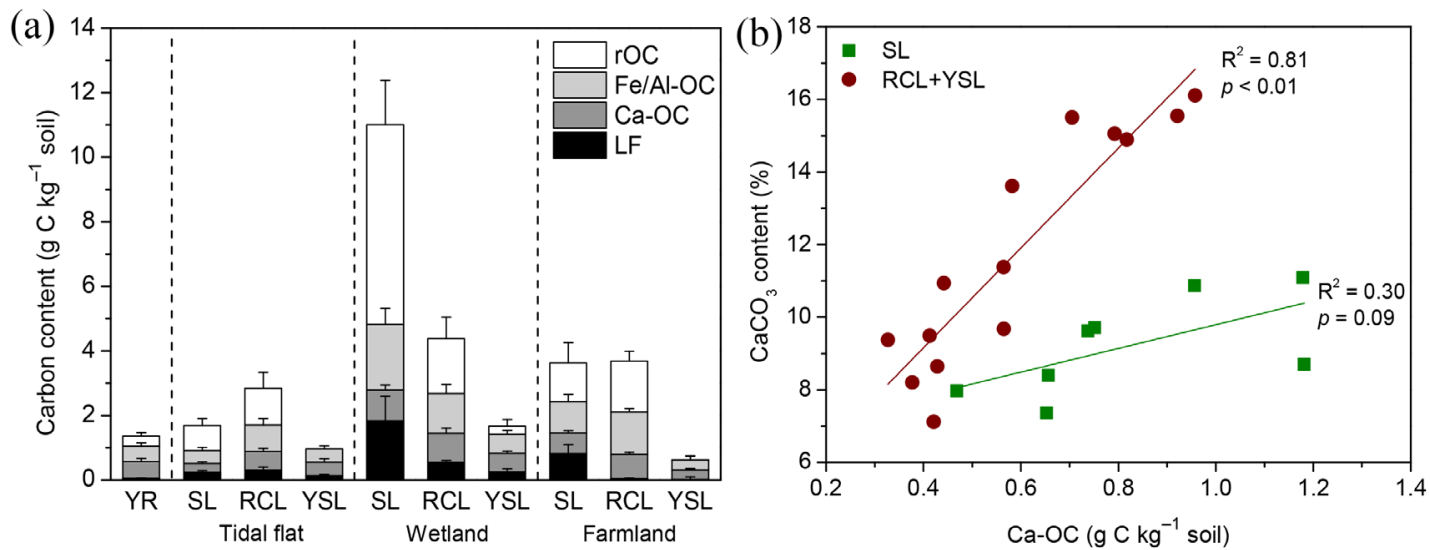

(c)

(d)
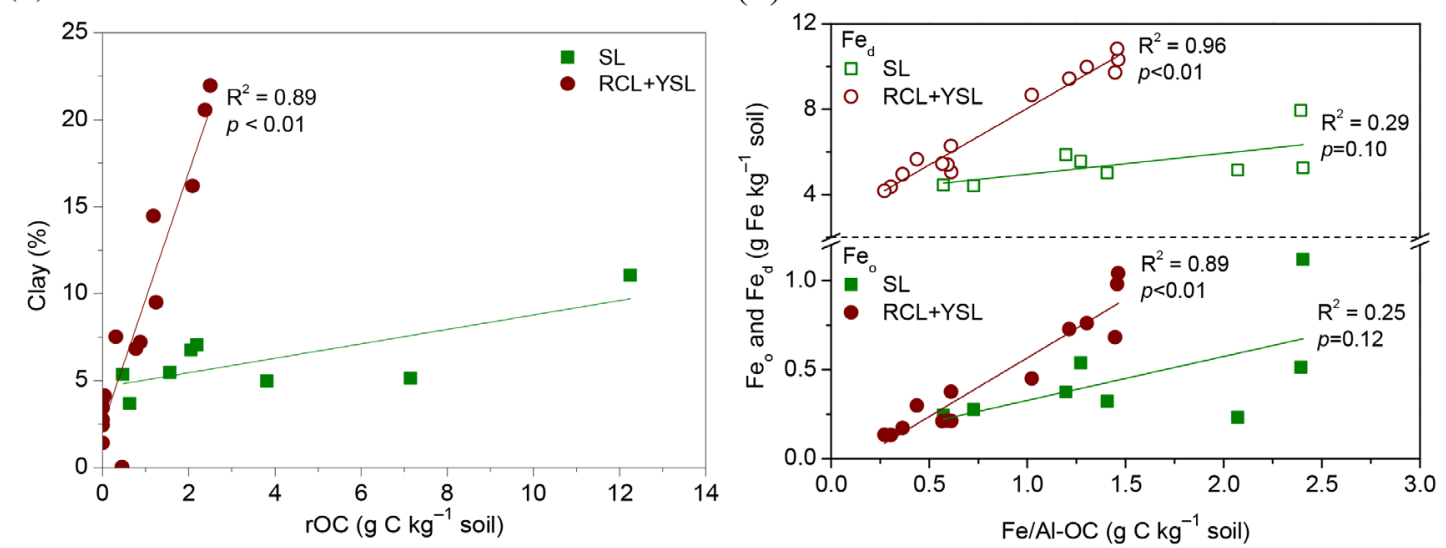

F I G U R E 4 Carbon fractions obtained by chemical fractionation in the Yellow River sediment (YR) and different soil layers (SL, surface layer; RCL, red clay layer; YSL, yellow silt layer). (a) Showing carbon fraction contents in different land-use types; (b), (c) and (d) showing correlations between Ca-bound carbon $(\mathrm{Ca}-\mathrm{OC})$ and $\mathrm{CaCO}_{3}$ contents (b), between residual carbon (rOC) and clay content (c), and between $\mathrm{Fe} / \mathrm{Al}$-bound carbon $(\mathrm{Fe} / \mathrm{Al}-\mathrm{OC})$ and amorphous Fe oxyhydrates $\left(\mathrm{Fe}_{\mathrm{o}}\right)$ and free $\mathrm{Fe}$ oxyhydrates $\left(\mathrm{Fe}_{\mathrm{d}}\right)(\mathrm{d})$, respectively $[$ Color figure can be viewed at wileyonlinelibrary.com]

used for measurement of ${ }^{14} \mathrm{C}$ activity at Beta Analytic Inc., Florida, USA, using standard accelerator mass spectrometry (AMS) delivery analysis. The errors of $\Delta^{14} \mathrm{C}$ measurements ranged from $1 \%$ to $3 \%$. Results are expressed as the fraction of modern carbon $\left(\mathrm{F}_{\bmod }\right)$, with values $>1 \mathrm{~F}_{\text {mod }}$ indicating the presence of (modern) bomb ${ }^{14} \mathrm{C}$, whereas values $<1 \quad \mathrm{~F}_{\text {mod }}$ indicate that the OC has been formed from atmospheric $\mathrm{CO}_{2}$ before 1950 (Schuur, Druffel, \& Trumbore, 2016). Assuming that a large portion of OC in deltaic soils, especially subsoil, is sourced from riverine $\mathrm{OC}$, we used an end member mixing model proposed by Galy, Beyssac, France-Lanord, and Eglinton (2008) to obtain fossil OC ( $\left.\mathrm{OC}_{\text {fossil }}\right)$ and biospheric $\mathrm{OC}\left(\mathrm{OC}_{\mathrm{bio}}\right)$ derived from aboveground biomass, soils and riverine autotrophic living organisms. The mixing equations are shown as follows:

$$
\mathrm{F}_{\text {mod }}=\left(\mathrm{OC}_{\text {fossil }} / \mathrm{OC}\right) \times \mathrm{F}_{\text {mod_fossil }}+\left(\mathrm{OC}_{\text {bio }} / \mathrm{OC}\right) \times \mathrm{F}_{\text {mod_bio. }} \text {. }
$$

$$
\begin{aligned}
\text { As } F_{\text {mod_fossil }} & =0 \text { and } \mathrm{OC}=\mathrm{OC}_{\text {fossil }}+\mathrm{OC}_{\text {bio }} \\
: \text { Modern } \mathrm{C} & =\mathrm{OC} \times \mathrm{F}_{\text {mod_bio }}-\mathrm{OC}_{\text {fossil }} \times \mathrm{F}_{\text {mod_bio, }}
\end{aligned}
$$

where $\mathrm{F}_{\text {mod_fossil }}$ and $\mathrm{F}_{\text {mod_bio }}$ represent the ${ }^{14} \mathrm{C}$ activity of the fossil $\left(\mathrm{F}_{\text {mod_fossil }}\right)$ and biospheric pool $\left(\mathrm{F}_{\text {mod_bio }}\right)$. In Equation (2), Modern $\mathrm{C}=\mathrm{OC} \times \mathrm{F}_{\text {mod. }}$. The values of $\mathrm{OC}_{\text {fossil }}$ and $\mathrm{F}_{\text {mod_bio }}$ can both be determined from the slope and intercept of linear regression.

\subsection{Statistical analysis}

The differences among the soil layers and carbon fractions were evaluated with one-way analyses of variance $($ ANOVA) and Duncan's post-hoc test (alpha $=0.05$ ) Pearson correlation analysis was conducted to detect relationships among the variables investigated. Heat maps were created of Spearman correlation matrices. Statistical analysis was performed using SPSS Statistics 20.0 for the 
(a)

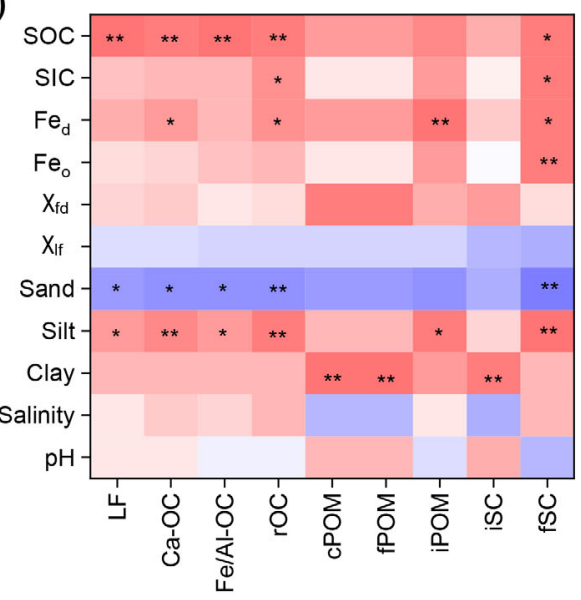

(c)

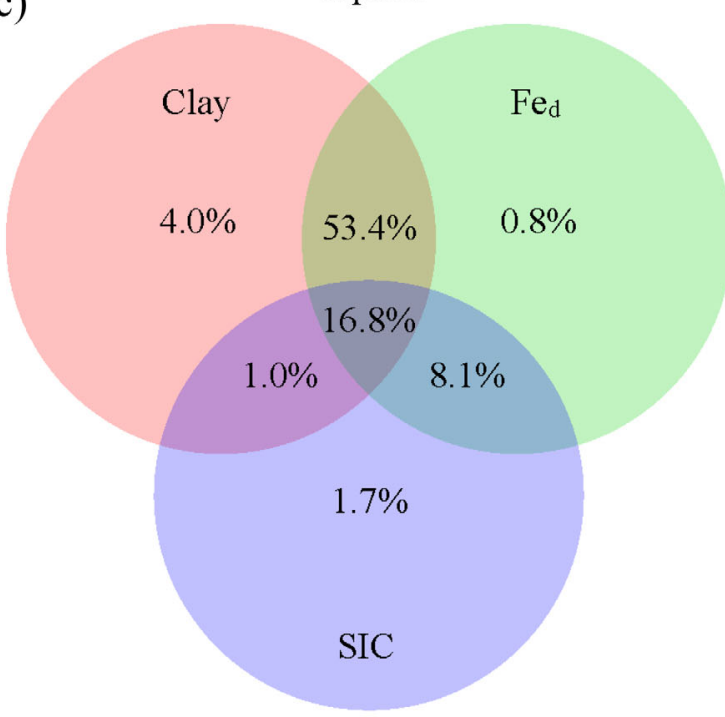

(b)

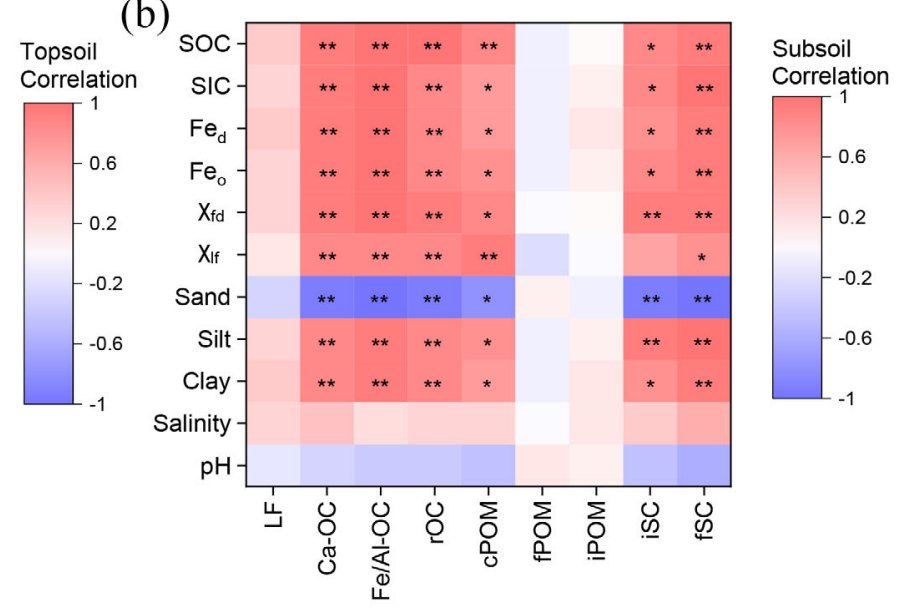

(d)

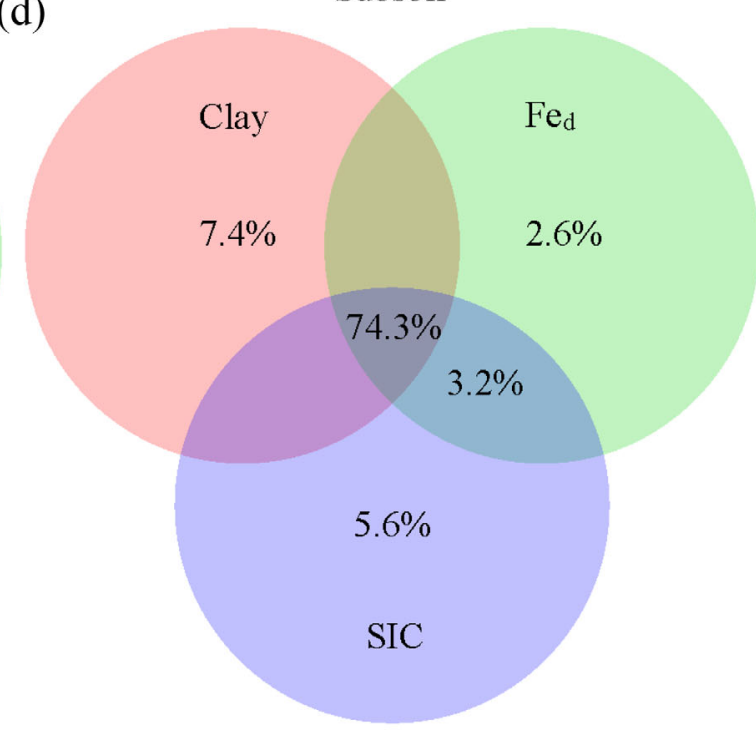

F I G U RE 5 Heat maps of Spearman's rank correlations $\left({ }^{* *} p<0.01,{ }^{*} p<0.05\right)$ between OC fractions obtained by physical and chemical fractionations and soil properties shown in Table 1 from (a) topsoil and (b) subsoil and variation partitioning analysis of the relative contributions of clay, free $\mathrm{Fe}$ oxyhydrates $\left(\mathrm{Fe}_{\mathrm{d}}\right.$ ) and soil inorganic carbon (SIC) to OC stabilization from (c) topsoil and (d) subsoil [Color figure can be viewed at wileyonlinelibrary.com]

Windows software package (SPSS Inc., Chicago, IL). Variation partitioning was performed in the $\mathrm{R}$ environment (v.3.6.3) using the function varpart in the package vegan (v.2.5-6) to analyse the influence of the soil particles and minerals on the OC fractions' stabilization.

\section{3 | RESULTS}

\section{1 | Soil physicochemical properties}

Soil $\mathrm{pH}$ was high in the study area, with a mean value above 8 (Table 1). Soil salinity presented an increasing trend from the Yellow River sediment to the surface layer of the tidal flat and wetland, and then decreased after cultivation. The clay content followed a similar trend. Changes in relative abundance and grain size of magnetic minerals can be used to trace the potential weathering history of the source region (Liu et al., 2012). Increased $\chi_{\mathrm{lf}}$ and $\chi_{\mathrm{fd}} \%$ values correspond to increased weathering of parent materials. There were no significant differences $(p>0.05)$ in $\chi_{\mathrm{lf}}$ and $\chi_{\mathrm{fd}} \%$ values among different land-use types. The relatively high $\chi_{\mathrm{lf}}$ but low $\chi_{\mathrm{fd}} \%$ values of the Yellow River sediment suggest that it may be contaminated by metals and that $\chi_{\mathrm{fd}} \%$ values can better interpret soil genesis. The contents of $\mathrm{Fe}_{\mathrm{o}}$ and $\mathrm{Fe}_{\mathrm{d}}$ were highest in the wetland, whereas there were no clear differences $(p>0.05)$ between the tidal flat and farmland. The SIC content was high but soil OC content was much lower in the study area. The OC content increased significantly to 
the highest in the surface layer of the wetland, but dropped sharply in the surface layer of the farmland.

The red clay layer had significantly higher values of clay, $\chi_{\mathrm{lf}}, \chi_{\mathrm{fd}} \%, \mathrm{Fe}_{\mathrm{d}}$ and SIC than the surface and yellow silt layer $(p<0.05)$, indicating its higher contents of clay minerals, iron oxides and carbonates and higher weathering degree. The $\mathrm{OC}$ content in the red clay layer was comparable to that in the surface layer and much higher than that in the yellow silt layer of the tidal flat and farmland. The OC content in the red clay layer generally increased in the order of tidal flat, farmland and wetland, indicating that the red clay layer had potential to accumulate young carbon from topsoil.

\section{2 | Soil OC fractions obtained by physical fractionation}

Across all land-use types and soil layers, OC was dominated by fSC (40-80\%) (Figures 3a and S1a). In the surface layer of wetland and farmland, about $20 \%$ of OC was present in cPOM, whereas $\mathrm{CPOM}$ in the other soil layers was nearly absent ( $<5 \%$ of OC). In subsoil layers, the iSC fraction in the red clay layer stored more OC compared to the yellow silt layer. The percentages of the iSC fraction in the red clay layer of wetland $(10.8 \%)$ and farmland $(12.2 \%)$ were also highest compared to the surface layer and yellow silt layer.

The $\delta^{13} \mathrm{C}$ values of the $\mathrm{OC}$ fractions in the surface layer and yellow silt layer showed an increasing trend in the order of $\mathrm{cPOM}<\mathrm{fPOM}<\mathrm{iPOM}<\mathrm{iSC}<\mathrm{fSC}$ (Figure $3 \mathrm{~b}$ ). The $\delta^{13} \mathrm{C}$ patterns of OC fractions in the Yellow River sediment and red clay layer were more variable. The values of cPOM in the Yellow River sediment and red clay layer were more positive. Considering the low salinity of the Yellow River sediment, the more positive $\delta^{13} \mathrm{C}$ values may be attributed to the contribution of aged terrestrial $\mathrm{OC}$ rather than marine OC. Accordingly, the more negative $\delta^{13} \mathrm{C}$ values of $\mathrm{fPOM}$, iSC and fSC in the Yellow River sediment were associated with more fresh terrestrial OC input, whereas the more positive $\delta^{13} \mathrm{C}$ values of iSC and fSC in the red clay layer indicated more aged terrestrial $\mathrm{OC}$ input.

\section{3 | Soil OC fractions obtained by chemical fractionation}

Results of chemical fractionation revealed a similar distribution pattern of OC fractions within the same soil layers from different land-use types (Figure $4 \mathrm{a}$ ). In the surface and red clay layer, the fractions generally followed the order of $\mathrm{LF} \quad(12.8 \%)<\mathrm{Ca}-\mathrm{OC} \quad(17.8 \%)<\mathrm{Fe} / \mathrm{Al}-\mathrm{OC}$ $(27.2 \%)<\mathrm{rOC}(42.2 \%)$ (Figure S1b). In the Yellow River sediment and yellow silt layer, $\mathrm{Fe} / \mathrm{Al}-\mathrm{OC}$ and $\mathrm{Ca}-\mathrm{OC}$ were the dominant fractions and made up about 35-40\% of total OC, respectively.

In the red clay-yellow silt layer sequence, significantly positive correlations were observed between $\mathrm{Ca}-$ $\mathrm{OC}$ and $\mathrm{CaCO}_{3}$, between $\mathrm{Fe} / \mathrm{Al}-\mathrm{OC}$ and $\mathrm{Fe}_{\mathrm{o}}$ and $\mathrm{Fe}_{\mathrm{d}}$ and between rOC and clay (Figure $4 \mathrm{~b}-\mathrm{d}$ ). For the surface layer, a significantly positive correlation was only observed between rOC and clay. This indicated that rOC may be mainly associated with clay minerals.

\section{4 | Radiocarbon content}

Because fSC was a dominant fraction in all soil layers from different land-use types (Figures 3 and S1a),
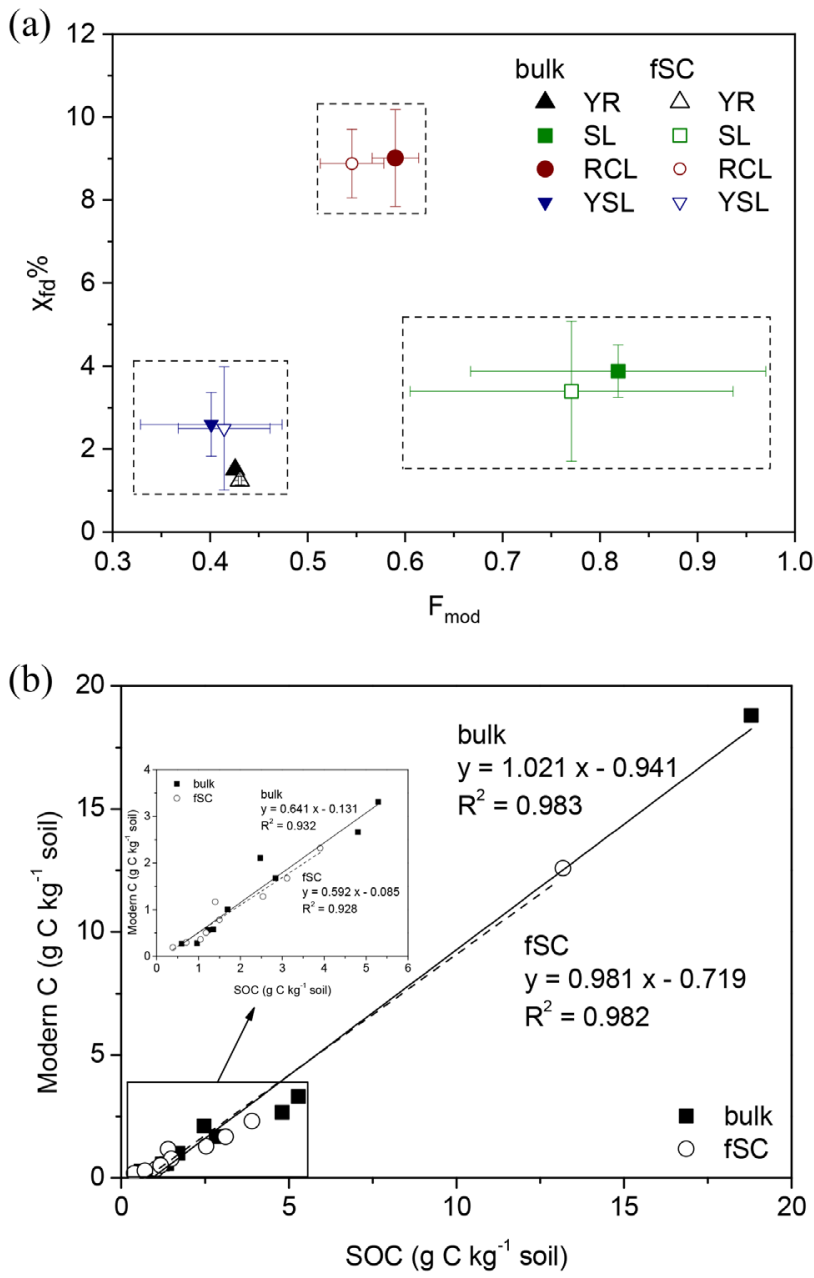

F I G U R E 6 Activity of ${ }^{14} \mathrm{C}$ (expressed as fraction modern carbon, $\mathrm{F}_{\text {mod }}$ ) in bulk and fSC fraction samples (surface layer [SL], red clay layer [RCL] and yellow silt layer [YSL] from one typical soil profile of tidal flat, wetland and farmland together with the Yellow River sediment [YR]). (a) Showing frequency dependent susceptibility $\left(\chi_{\mathrm{fd}} \%\right)$ vs. $\mathrm{F}_{\text {mod }}$; (b) showing correlation between modern $\mathrm{C}\left(\mathrm{OC} \times \mathrm{F}_{\mathrm{mod}}\right)$ and soil $\mathrm{OC}(\mathrm{SOC})$ [Color figure can be viewed at wileyonlinelibrary.com] 
radiocarbon contents were determined for $\mathrm{OC}$ in the bulk and fSC fraction of different soil layers (Figure 6). These data showed that OC ages were quite similar between the bulk and fSC fraction (Figure 6a). It was notable that although the red clay layer had the highest weathering intensity, as indicated by the highest $\chi_{\mathrm{fd}} \%$ values, the average $F_{\text {mod }}$ value of the red clay layer (bulk 0.59, fSC 0.55) was much higher than that of the yellow silt layer (bulk 0.41, fSC 0.40) and Yellow River sediment (bulk 0.43 , fSC 0.43), indicating that the red clay layer received a greater amount of younger OC. The average $F_{\text {mod }}$ value in the bulk of the red clay layer, yellow silt layer and Yellow River sediment corresponded to calibrated ages of 4,203, 7,453 and 6,820 BP respectively. The highest $F_{\text {mod }}$ values of 1.01 (bulk) and 0.96 (fSC) were obtained in the surface layer of wetland, corresponding to calibrated ages of modern and $370 \mathrm{BP}$, respectively.

The distinct radiocarbon ages indicated that soil OC in river deltas was a binary mixture of fossil OC and biospheric OC (Galy et al., 2008; Trumbore, 2009). Although it was known that the ${ }^{14} \mathrm{C}$ activity of fossil $\mathrm{OC}\left(\mathrm{OC}_{\text {fossil }}\right)$ is 0 , both the contribution of $\mathrm{OC}_{\text {fossil }}$ to total $\mathrm{OC}$ and the ${ }^{14} \mathrm{C}$ activity of the biospheric pool ( $\left.\mathrm{F}_{\text {mod_bio }}\right)$ are unknown. An end member mixing analysis (Section 2) developed by Galy et al. (2008) was used to determine the two unknowns. The $\mathrm{F}_{\text {mod_bio }}$ values of the bulk and fSC fraction were 1.02 and 0.98 , corresponding to calibrated ages of modern and $142 \mathrm{BP}$, respectively. However, if we remove the data of the wetland surface layer, $F_{\text {mod_bio }}$ values of the bulk and fSC fraction were 0.64 and 0.59 , corresponding to calibrated ages of 3,569 and 4,203 BP, respectively (Figure $6 \mathrm{~b}$, inset). Modern $\mathrm{OC}$ contributes significantly to $\mathrm{OC}$ in wetland topsoil. The $\mathrm{OC}_{\text {fossil }}$ contents in the bulk and fSC fractions excluding the wetland

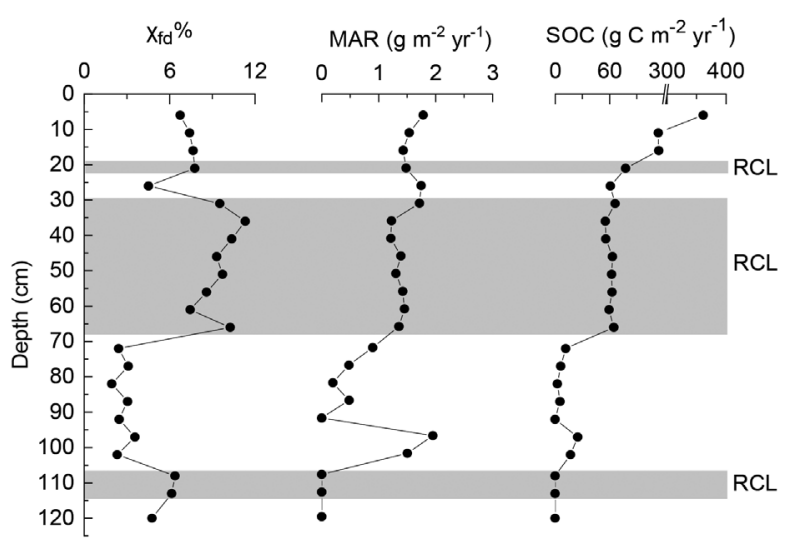

FI G URE 7 Depth distributions of frequency-dependent susceptibility $\left(\chi_{\mathrm{fd}} \%\right)$, mass accumulation rate (MAR) and soil OC (SOC) accumulation rate in a typical high-resolution soil profile of wetland (Y23) with red clay layer (RCL) surface layer dataset were 0.20 and $0.14 \mathrm{~g} \mathrm{~kg}^{-1}$, corresponding to 9.93 and $9.67 \%, 4.99$ and $4.53 \%, 23.5$ and $23.0 \%, 17.6$ and $11.9 \%$ of total bulk and fSC OC in the surface layer, red clay layer, yellow silt layer and Yellow River sediment, respectively.

\section{4 | DISCUSSION}

\section{1 | Land-use types and fine particles controlling OC storage in topsoil}

In our study, conversion from tidal flat to wetland substantially increased OC by $84 \%$ in the top $20 \mathrm{~cm}$, whereas cotton cultivation decreased OC by $66 \%$. The increased $\mathrm{OC}$ input in the wetland has directly promoted $\mathrm{OC}$ accumulation in the fractions of CPOM and LF and OC stabilization in the mineral fractions (e.g., fSC and rOC). OC accumulation in the mineral fractions occurs not only due to new OC input, but also as a result of a transfer of old OC from CPOM to these fractions (Del Galdo, Six, Peressotti, \& Francesca Cotrufo, 2003; Stewart et al., 2008). This indicates a substantial potential of OC storage under wetland systems. Our results indicate that cotton cultivation strongly decreases the OC content of all fractions and decreases the proportional weight of ASC and rOC (Figures 3a, 4a and Figure S1). This can be attributed to tillage being a highly disturbing management practice, which alters aggregate dynamics by enhancing the turnover time of $\mathrm{cPOM}$, thus decreasing the formation of the more stabilized $\mathrm{C}$ fractions, such as iPOM and silt \& clay associated C (Stewart et al., 2008).

Previous studies have found strong evidence for 30 to $80 \%$ of OC decline when natural vegetation ecosystems are converted to farmland (Poeplau et al., 2011; Wei, Shao, Gale, \& $\mathrm{Li}, 2015)$. Contrasting with the OC declines, many field studies have shown that reducing tillage often increases storage of OC (Cates, Ruark, Hedtcke, \& Posner, 2016; Chivenge, Murwira, Giller, Mapfumo, \& Six, 2007). The key mechanisms that affect OC decline in cultivated soils include erosion, lower OC inputs, reduced stabilization of OC due to aggregate breakdown, and promoted OC decomposition by increased soil temperature and aeration (Chivenge et al., 2007; Stewart et al., 2008; Wiesmeier et al., 2019). A striking difference in OC fractions between the topsoil and subsoil is the relatively high contents of CPOM and LF in topsoil (Figures 3a and 4a). Therefore, abiotic and biotic formation of macroaggregates is a main mechanism for formation and stabilization of the topsoil structure and results in sequestration of fresh OC input, especially for wetland.

Coastal wetland that develops on deltaic topset has productivity and capacity to enhance sediment accretion 
and to build a large carbon deposit, acting as an important carbon sink and providing a natural coastline protection against sea level rise (Duarte, Losada, Hendriks, Mazarrasa, \& Marbà, 2013; Shields et al., 2017). Syvitski et al. (2009) estimated that the rates of sea level rise in the Yellow River delta ranged from $0.8 \mathrm{~cm}_{\text {year }}{ }^{-1}$ to $2.3 \mathrm{~cm}$ year $^{-1}$. The accumulation rate of the new Yellow River delta lobe sediment is estimated to be 5$18.6 \mathrm{~cm}$ year $^{-1}$ on the delta front slope, $2 \mathrm{~cm}$ year $^{-1}$ at the toe of the slope (Zhou et al., 2016), and $1 \mathrm{~cm}$ year $^{-1}$ in the coastal wetland (Figure 7). The accumulation rates are higher than or comparable with the rates of sea level rise. The $\mathrm{OC}$ accumulation rate in the top $20 \mathrm{~cm}$ of the wetland is estimated to be $167 \mathrm{~g} \mathrm{C} \mathrm{g} \mathrm{m}^{-2}$ year $^{-1}$ (Figure 7), exceeding that in the soils of terrestrial forests by 35 -fold (McLeod et al., 2011). Moreover, restoration projects that introduce tidal flow and freshwater have promoted rapid accumulation and slow decomposition of $\mathrm{OC}$ in the coastal wetlands by facilitating colonization, sediment trapping and belowground $\mathrm{OC}$ production and by slowing respiration (Spivak et al., 2019; Yin et al., 2019; Zhao et al., 2018).

Among the major soil OC stabilization mechanisms, the formation of organo-mineral complexes in the fine particles (silt and clay) is regarded as quantitatively most important (McNally et al., 2017; Wiesmeier et al., 2019). Beare et al. (2014) reported that the OC content of the fine particles (fine silt + clay) in the New Zealand topsoil was assumed to comprise $85 \%$ of the total OC. In our dataset, there is a strong positive correlation between fine particles (clay or silt) and all OC fractions and between $\mathrm{Fe}_{\mathrm{d}}$ and $\mathrm{Ca}-\mathrm{OC}, \mathrm{rOC}$, iPOM and fSC (Figure 5a). These two factors can explain $53.4 \%$ of the variation in OC sequestrated by different $\mathrm{OC}$ fractions in topsoil (Figure 5c). The soil OC associated with the fine mineral fraction is generally considered as stable $\mathrm{OC}$ due to its relatively long turnover time. In this regard, clay minerals and siltsized microaggregates seem to be of particular importance for long-term carbon storage in topsoil. Although the soil OC associated with the fine particles is relatively resistant to changes in management, intensive management can result in losses of OC from the fine particles (Cates et al., 2016; Chivenge et al., 2007). This is consistent with the significant drop in clay and silt content and soil OC content by land conversion from wetland to farmland (Table 1) because reclamation in decades to century scales enhances soil structural degradation and aggregate breakdown (Chivenge et al., 2007; Cui et al., 2014). Therefore, managements such as crop rotation, increasing organic amendment inputs and reduced tillage, which can increase POM and aggregate OC, should be given high priority for improving carbon sequestration in topsoil (Cates et al., 2016).

\section{2 | Pedological characteristics controlling OC storage in subsoil}

In our study, although land-use change strongly influenced OC fractions in the surface layer, it does not appear to have altered the fractions in the red clay layer. The OC fractions are significantly positively related to the contents of clay, iron oxide and carbonate in the red clay-yellow silt layer sequence (Figure $4 \mathrm{~b}-\mathrm{d}$ ). Interaction of $\mathrm{OC}$ with mineral surfaces is acknowledged to be a crucial mechanism for OC stabilization in subsoil (Chabbi et al., 2009; Wiesmeier et al., 2019). The contents of clay minerals, $\mathrm{Fe}_{\mathrm{d}}, \mathrm{Fe}_{\mathrm{o}}$ and carbonate in the red clay layer are substantially higher than those in the yellow silt layer (Table 1; Li et al., 2019). The clay mineral in the red clay layer is dominated by illite (2:1 clay) (Li et al., 2019), exhibiting high cation exchange capacity and specific surface area, which has high capacity to adsorb organic materials (Kaiser \& Guggenberger, 2003). The high clay content of the red clay layer (also the surface layer in wetland) provides potential for the stabilization of OC by association of organic materials with clay minerals.

In our study, $\mathrm{Fe} / \mathrm{Al}$ oxides and carbonate contribute almost equally to OC storage, both accounting for about $20-30 \%$ of the OC in the red clay layer and $30-40 \%$ in the Yellow River sediment and yellow silt layer (Figures $4 \mathrm{a}$ and $\mathrm{S} 1 \mathrm{~b}) . \mathrm{Fe} / \mathrm{Al}$ oxides are key geochemical factors that involve the mobilization and stabilization of $\mathrm{OC}$ in deltaic soils (Lalonde, Mucci, Ouellet, \& Gélinas, 2012). Fe-oxides and hydroxides have particularly high specific surface areas (SSA), resulting in a potentially greater affinity for OC than other mineral surfaces such as clay minerals (Wiesmeier et al., 2019). In wetland, Fe(II) can be oxidized to Fe(III) under aerobic conditions, and the decline of $\mathrm{Fe}(\mathrm{II})$ may be accompanied by reduced activities of oxidative and hydrolytic enzymes, thereby enhancing OC preservation (Wang, Wang, He, \& Feng, 2017). Furthermore, chemically stable $\mathrm{Fe}-\mathrm{OC}$ complexes can be formed via adsorption and coprecipitation with the newly formed reactive $\mathrm{Fe}(\mathrm{III})$ (hydro)oxides. Such $\mathrm{Fe}-\mathrm{OC}$ complexes are estimated to stabilize $21.5 \%$ of OC in coastal soils and sediments and $37.8 \%$ of OC in US forest soils (Lalonde et al., 2012; Zhao et al., 2016). Fe/Al-OC contents in the Yellow River delta soils are within these ranges.

Although the role of iron oxides in preserving OC has recently been well documented in soils, interactions between OC and calcium have typically received less attention. Rowley, Grand, and Verrecchia (2018) reported that at pH 68 , inner- and outer-sphere $\mathrm{Ca}^{2+}$ bridging or flocculation and precipitation by $\mathrm{Ca}^{2+}$ dominate $\mathrm{Ca}-\mathrm{OC}$ stabilization; at pH 8-9, sorption and cementation of aggregates by carbonate dominate $\mathrm{Ca}-\mathrm{OC}$ stabilization. Because soil $\mathrm{pH}$ is in the range of 8 to 9 and average SIC contents exceed $10 \mathrm{~g} \mathrm{~kg}^{-1}$ in all the soil layers of the Yellow River delta (Table 1), it can be 
expected that the dominant stabilization mechanisms are adsorption by the carbonate and occlusion within carbonatecemented aggregates ( $\mathrm{Li}, \mathrm{Fu}$, et al., 2020). The difference in OC content between the red clay and yellow silt layer can be mainly attributed to the different contents of clay minerals, iron oxides and carbonates, highlighting the importance of OC-mineral interactions in subsoil.

Besides mineral stabilization, the mineral-dominated deltaic soils and sediments often exhibit high accumulation rates of OC. Shields et al. (2017) found that although showing low OC content (about $4 \mathrm{~g} \mathrm{~kg}^{-1}$ ), the OC accumulation rate in the Wax Lake delta is up to $250 \pm 23 \mathrm{~g} \mathrm{C} \mathrm{g} \mathrm{m}^{-2}$ year $^{-1}$, which is comparable to that of coastal vegetated ecosystems. The OC accumulation rates of the red clay and yellow silt layer are $52.7 \pm 26.1$ and $27.0 \pm 17.6 \mathrm{~g} \mathrm{C} \mathrm{g} \mathrm{m}^{-2}$ year $^{-1}$, respectively (Figure 7). The red clay layer with much higher mineral contents has a twofold higher $\mathrm{OC}$ accumulation rate than the yellow silt layer. This result further demonstrates that the association between $\mathrm{OC}$ and mineral particles is a key mechanism for OC accumulation in river deltas.

Our previous study has shown that pedological characteristics are strongly associated with the composition of soil mineralogy in subsoil layers, resulting in shifts in carbon storage within the soil profile (Li et al., 2019, 2020b). The pedogenesis chemical weathering reactions and mechanical sorting process lead to significant accumulation of secondary minerals, including pedogenic Fe-oxides, phyllosilicates and carbonates in the red clay layer. In contrast, these pedogenic minerals are deficient in the yellow silt layer. The difference between the stabilized $\mathrm{OC}$ in subsoil layers compared to the topsoil is that the OC fractions in subsoil layers are soil layer-type specific and dependent on pedological characteristics, showing strong correlations between OC fractions and soil texture, magnetic properties, iron oxides and carbonate (Figure 5b). These three factors can jointly explain $74.3 \%$ of the variation in OC sequestrated by different OC fractions in subsoil (Figure 5d). This is in accordance with previous studies which also mentioned that OC dynamics in topsoil were predominantly influenced by supply of fresh organic material and water potential whereas subsoil OC was mainly regulated by the composition of the mineral phase (Matteodo et al., 2018; Salomé et al., 2010). Our study thus evidenced that the contrasting pedological characteristics within a soil profile can lead to heterogeneous distribution of stabilized OC compounds (Rumpel \& Kögel-Knabner, 2011).

\section{3 | Contribution of old-aged allochthonous $\mathrm{OC}$ in subsoil}

The $\mathrm{OC}_{\text {fossil }}$ proportions in the bulk and fSC fractions are similar to those in the Amazon system $\left(\mathrm{OC}_{\text {fossil }}\right.$ reaches
3-10\% in suspended load and up to about $50 \%$ in bedload) (Bouchez et al., 2014), but lower than those in the Ganges-Brahmaputra system $\left(\mathrm{OC}_{\text {fossil }}\right.$ reaches $20 \%$ in suspended load and $100 \%$ in bedload) (Galy et al., 2007) and Andean system $\left(\mathrm{OC}_{\text {fossil }}\right.$ reaches $80 \%$ in suspended load) (Clark et al., 2013). Our measurements of ${ }^{14} \mathrm{C}$ content of $\mathrm{OC}$ in the Yellow River delta demonstrate that fresh $\mathrm{OC}$ derived from local biomass production partially controls the amount of topsoil OC, whereas pre-aged and fossil OC contribute significantly to the subsoil. Similarly, very old particulate $\mathrm{OC}$ has also been measured in the Yellow River basin (2,000-8,000 years), which mainly comes from pre-aged $\mathrm{OC}$ (i.e., OC that has undergone long-term storage in mineral soils or floodplain sediments) (60-70\%) and fossil OC (17-27\%) (Xue et al., 2017). The old particulate OC can be derived mainly from the eroded aged $\mathrm{OC}$ and fossil carbon in fossil-fuel-based synthetic fertilizers or petroleum products in the basin (Butman, Wilson, Barnes, Xenopoulos, \& Raymond, 2015). This indicates that millennia-old allochthonous $\mathrm{OC}$ is the main component of OC that is effectively preserved in the Yellow River delta.

In our study, the red clay layer with the highest weathering intensity shows a much younger age of $\mathrm{OC}$ than that of the yellow silt layer (Figure 6a). It is known that the residence time of stabilized $\mathrm{OC}$ in soils is particularly related to the type of minerals and their different surface areas and surface charges (Trumbore, 2009). Chorover, Amistadi, and Chadwick (2004) reported that OC with the longest residence times (thousands to tens of thousands of years) was associated with poorly crystalline or nanocrystalline primary weathering products (ferrihydrate, allophone, imogolite) and $\mathrm{OC}$ with shorter residence times (thousands of years) was associated with secondary weathering products such as crystalline clays. The younger OC age in the red clay layer that contains the largest amounts of highactivity Fe-oxides and crystalline clays confirms the predominant role of minerals' surface sorption in the protection of organic matter from biodegradation.

Exchange between dissolved $\mathrm{OC}$ and mineralassociated OC plays a critical role in $\mathrm{OC}$ cycling in coastal and inland aquatic ecosystems (Pérez, MoreiraTurcq, Gallard, Allard, \& Benedetti, 2011). Globally, the dissolved OC (mean modern) is much younger than the particulate OC (mean 1,800 years) (Marwick et al., 2015), which is also the case for the Yellow River (Xue et al., 2017). The relatively younger age of OC in the red clay layer suggests that secondary minerals and oxides have the ability to adsorb dissolved OC during riverine transport. After deposition, the red clay layer may also capture labile dissolved OC sourced from topsoil through preferential flow, as well as belowground OC derived from microbial activities (Rumpel \& Kögel-Knabner, 
2011; Sokol \& Bradford, 2019). Our results are consistent with studies showing that in subsoil the presence of carbon is not homogeneously distributed but spatially variable (Chabbi et al., 2009; Salomé et al., 2010). These findings imply that mineral-associated $\mathrm{OC}$ is not necessarily related to old OC or refractory OC. The highly reactive, clay-sized secondary minerals and iron oxides produced under moderate weathering conditions are capable of stabilizing both fresh and aged OC in transportation, deposition and post-pedogenic alteration.

\section{5 | CONCLUSIONS}

Our results reveal that particulate (autochthonous dominant) and mineral-associated (allochthonous dominant) OC are two important organic matter pools affecting OC storage in deltaic ecosystems. In topsoil, particulate OC with a modern age, as a largely plant-derived and relatively vulnerable fraction, plays a significant role of OC storage in wetland. In contrast, secondary minerals, including clays, $\mathrm{Fe} / \mathrm{Al}$ oxides and pedogenic carbonates, exert significant controls over subsoil OC stock across the Yellow River delta, exceeding the importance of land-use types, particularly in soil layers with fine particle sizes (e.g., red clay layer). We show that aged $\mathrm{OC}$ is a major component of $\mathrm{OC}$ in river delta soils and contributes to $\mathrm{OC}$ at all depths. In the red clay layer, surprisingly, OC appeared to be fresher with younger radiocarbon ages in this stronger developed layer compared to the yellow silt layer, suggesting a stratified $\mathrm{OC}$ within the soil profile. Such stratification is probably due to the stabilization of fresher dissolved OC by clay-sized secondary minerals. These results suggest that controls on OC dynamics in the topsoil and subsoil of a river delta may be different. Specific sedimentary layers in coastal ecosystems should be taken into account when the coastal OC-cycle process is to be studied under a changing environment.

\section{ACKNOWLEDGEMENTS}

This research was supported by the National Natural Science Foundation of China (41701263, 42007022, 41991330, 41807418). We thank Pingsong Lu for his help in OC fractionation. We also thank Ying Liu for his suggestions on statistical analyses.

\section{AUTHOR CONTRIBUTIONS}

Yuan Li: Conceptualization; data curation; formal analysis; funding acquisition; investigation; methodology; writing-original draft; writing-review \& editing. Chuancheng Fu: Data curation; formal analysis; funding acquisition; investigation; methodology; writingoriginal draft. Lin Zeng: Data curation; formal analysis; funding acquisition; methodology. Qian Zhou: Data curation; investigation; methodology. Haibo Zhang: Data curation; investigation. Chen Tu: Data curation; investigation. Lianzhen Li: Data curation; investigation.

\section{CONFLICT OF INTEREST}

The authors confirm that there is no conflict of interest.

\section{DATA AVAILABILITY STATEMENT}

The data that support the findings of this study are available from the corresponding author upon reasonable request.

\section{ORCID}

Yuan Li (i) https://orcid.org/0000-0002-5974-0295

Chuancheng Fu (10) https://orcid.org/0000-0001-5982-6809

Yongming Luo (i) https://orcid.org/0000-0002-2217-3207

\section{REFERENCES}

Arias-Ortiz, A., Masqué, P., Garcia-Orellana, J., Serrano, O., Mazarrasa, I., Marba, N., ... Duarte, C. M. (2018). Reviews and syntheses: ${ }^{210} \mathrm{~Pb}$-derived sediment and carbon accumulation rates in vegetated coastal ecosystems - setting the record straight. Biogeosciences, 15, 6791-6818.

Beare, M., McNeill, S., Curtin, D., Parfitt, R., Jones, H., Dodd, M., \& Sharp, J. (2014). Estimating the organic carbon stabilisation capacity and saturation deficit of soils: A New Zealand case study. Biogeochemistry, 120, 71-87.

Bianchi, T. S., \& Allison, M. A. (2009). Large-river delta-front estuaries as natural "recorders" of global environmental change. Proceedings of the National Academy of Sciences of the United States of America, 106, 8085-8092.

Bianchi, T. S., Cui, X. Q., Blair, N. E., Burdige, D. J., Eglinton, T. I., \& Galy, V. (2018). Centers of organic carbon burial and oxidation at the land-ocean interface. Organic Geochemistry, 115, 138-155.

Bouchez, J., Galy, V., Hilton, R. G., Gaillardet, J., MoreiraTurcq, P., Pérez, M. A., ... Maurice, L. (2014). Source, transport and fluxes of Amazon River particulate organic carbon: Insights from river sediment depth-profiles. Geochimica et Cosmochimica Acta, 133, 280-298.

Butman, D. E., Wilson, H. F., Barnes, R. T., Xenopoulos, M. A., \& Raymond, P. A. (2015). Increased mobilization of aged carbon to rivers by human disturbance. Nature Geoscience, 8, 112-116.

Cates, A. M., Ruark, M. D., Hedtcke, J. L., \& Posner, J. L. (2016). Long-term tillage, rotation and perennialization effects on particulate and aggregate soil organic matter. Soil \& Tillage Research, 155, 371-380

Chabbi, A., Kögel-Knabner, I., \& Rumpel, C. (2009). Stabilised carbon in subsoil horizons is located in spatially distinct parts of the soil profile. Soil Biology and Biochemistry, 41, 256-261.

Chivenge, P. P., Murwira, H. K., Giller, K. E., Mapfumo, P., \& Six, J. (2007). Long-term impact of reduced tillage and residue management on soil carbon stabilization: Implications for conservation agriculture on contrasting soils. Soil \& Tillage Research, 94, 328-337.

Chorover, J., Amistadi, M. K., \& Chadwick, O. A. (2004). Surface charge evolution of mineral-organic complexes during 
pedogenesis in Hawaiian basalt. Geochimica et Cosmochimica Acta, 68, 4859-4876.

Clark, K. E., Hilton, R. G., West, A. J., Malhi, Y., Gröcke, D. R., Bryant, C. L., ... New, M. (2013). New views on old carbon in the Amazon River: Insight from the source of organic carbon eroded from the Peruvian Andes. Geochemistry, Geophysics, Geosystems, 14, 1644-1659.

Cotrufo, M. F., Ranalli, M. G., Haddix, M. L., Six, J., \& Lugato, E. (2019). Soil carbon storage informed by particulate and mineral-associated organic matter. Nature Geoscience, 12, 989-994.

Cui, J., Li, Z., Liu, Z. X., Ge, B. M., Fang, C. M., Zhou, C. L., \& Tang, B. (2014). Physical and chemical stabilization of soil organic carbon along a 500-year cultivated soil chronosequence originating from estuarine wetlands: Temporal patterns and land use effects. Agriculture, Ecosystems and Environment, 196, 10-20.

Day, J. W., Agboola, J., Chen, Z., D’Elia, C., Forbes, D. L., Giosan, L., ... Yañez-Arancibia, A. (2016). Approaches to defining deltaic sustainability in the 21st century. Estuarine, Coastal and Shelf Science, 183, 275-291.

Del Galdo, I., Six, J., Peressotti, A., \& Francesca Cotrufo, M. (2003). Assessing the impact of land-use change on soil $\mathrm{C}$ sequestration in agricultural soils by means of organic matter fractionation and stable C isotopes. Global Change Biology, 9, 1204-1213.

Doetterl, S., Berhe, A. A., Arnold, C., Bodé, S., Fiener, P., Finke, P., ... Boeckx, P. (2018). Links among warming, carbon and microbial dynamics mediated by soil mineral weathering. Nature Geoscience, 11, 589-593.

Duarte, C. M., Losada, I. J., Hendriks, I. E., Mazarrasa, I., \& Marbà, N. (2013). The role of coastal plant communities for climate change mitigation and adaptation. Nature Climate Change, 3, 961-968.

Fan, X., Pedroli, B., Liu, G., Liu, Q., Liu, H., \& Shu, L. (2012). Soil salinity development in the yellow river delta in relation to groundwater dynamics. Land Degradation and Development, $23,175-189$.

Galy, V., Beyssac, O., France-Lanord, C., \& Eglinton, T. (2008). Recycling of graphite during Himalayan erosion: A geological stabilisation of carbon in the crust. Science, 322, 943-945.

Galy, V., France-Lanord, C., Beyssac, O., Faure, P., Kudrass, H., \& Palhol, F. (2007). Efficient carbon burial in the Bengal fan sustained by the Himalayan erosional system. Nature, 450, 407-410.

Han, G. X., Chu, X. J., Xing, Q. H., Li, D. J., Yu, J. B., Luo, Y. Q., .. Rafique, R. (2015). Effects of episodic flooding on the net ecosystem $\mathrm{CO}_{2}$ exchange of a supratidal wetland in the Yellow River Delta. Journal of Geophysical Research: Biogeoscience, 120, 1506-1520.

Kaiser, K., \& Guggenberger, G. (2003). Mineral surfaces and soil organic matter. European Journal of Soil Science, 54, 219-236.

Lalonde, K., Mucci, A., Ouellet, A., \& Gélinas, Y. (2012). Preservation of organic matter in sediments promoted by iron. Nature, 483, 198-200.

Li, Y., Fu, C. C., Zeng, L., Zhou, Q., Zhang, H. B., \& Tu, C. (2020) Carbon accumulation in the red clay layer of the subsoil in a major river delta: Contribution of secondary carbonate. Catena, 186, 104391.

Li, Y., Zhang, H. B., Fu, C. C., Tu, C., Luo, Y. M., \& Christie, P. (2019). A red clay layer in soils of the Yellow River Delta: Occurrence, properties and implications for elemental budgets and biogeochemical cycles. Catena, 172, 469-479.
Li, Y., Zhang, H. B., Tu, C., Fu, C. C., Xue, Y., \& Luo, Y. M. (2016). Sources and fate of organic carbon and nitrogen from land to ocean: Identified by coupling stable isotopes with $\mathrm{C} / \mathrm{N}$ ratio. Estuarine, Coastal and Shelf Science, 181, 114-122.

Li, Y., Zhang, H. B., Tu, C., \& Luo, Y. M. (2018). Magnetic characterization of distinct soil layers and its implications for environmental changes in the coastal soils from the Yellow River Delta. Catena, 162, 245-254.

Li, Y. R., Shi, W. H., Aydin, A., Beroya-Eitner, M. A., \& Gao, G. H. (2020). Loess genesis and worldwide distribution. Earth-Science Reviews, 201, 102947.

Liu, Q. S., Roberts, A. P., Larrasoana, J. C., Banerjee, S. K., Guyodo, Y., Tauxe, L., \& Oldfield, F. (2012). Environmental magnetism: Principles and applications. Reviews of Geophysics, 50, RG4002.

Marwick, T. R., Tamooh, F., Teodoru, C. R., Borges, A. V., Darchambeau, F., \& Bouillon, S. (2015). The age of river transported carbon: A global perspective. Global Biogeochemical Cycles, 29, 122-137.

Matteodo, M., Grand, S., Sebag, D., Rowley, M. C., Vittoz, P., \& Verrecchia, E. P. (2018). Decoupling of topsoil and subsoil controls on organic matter dynamics in the Swiss Alps. Geoderma, $330,41-51$.

Mcleod, E., Chmura, G. L., Bouillon, S., Salm, R., Björk, M., Duarte, C. M., ... Silliman, B. R. (2011). A blueprint for blue carbon: Toward an improved understanding of the role of vegetated coastal habitats in sequestering $\mathrm{CO}_{2}$. Frontiers in Ecology and the Environment, 9, 552-560.

Mcnally, S. R., Beare, M. H., Curtin, D., Meenken, E. D., Kelliher, F. M., Pereira, R., ... Baldock, J. (2017). Soil carbon sequestration potential of permanent pasture and continuous cropping soils in New Zealand. Global Change Biology, 23, 45444555.

Milliman, J. D., \& Syvitski, J. P. (1992). Geomorphic/tectonic control of sediment discharge to the ocean: The importance of small mountainous rivers. The Journal of Geology, 100, 525-544.

Pérez, M. A., Moreira-Turcq, P., Gallard, H., Allard, T., \& Benedetti, M. F. (2011). Dissolved organic matter dynamic in the Amazon basin: Sorption by mineral surfaces. Chemical Geology, 286, 158-168.

Poeplau, C., Don, A., Vesterdal, L., Leifeld, J., Van Wesemael, B., Schumacher, J., \& Gensior, A. (2011). Temporal dynamics of soil organic carbon after land-use change in the temperate zone - carbon response functions as a model approach. Global Change Biology, 17, 2415-2427.

Qu, Y. X., Jin, Z. D., Wang, J., Wang, Y. Q., Xiao, J., Gou, L. F., ... $\mathrm{Xu}, \mathrm{X}$. (2020). The sources and seasonal fluxes of particulate organic carbon in the Yellow River. Earth Surface Process and Landforms, 45, 2004-2019.

Rowley, M. C., Grand, S., \& Verrecchia, É. P. (2018). Calciummediated stabilisation of soil organic carbon. Biogeochemistry, 137, 27-49.

Rumpel, C., \& Kögel-Knabner, I. (2011). Deep soil organic matter: A key but poorly understood component of terrestrial $\mathrm{C}$ cycle. Plant and Soil, 338, 143-158.

Saito, Y., Wei, H. L., Zhou, Y. Q., Nishimura, A., Sato, Y., \& Yokota, S. (2000). Delta progradation and chenier formation in the Huanghe (Yellow River) delta, China. Journal of Asian Earth Sciences, 18, 489-497. 
Salomé, C., Nunan, N., Pouteau, V., Lerch, T. Z., \& Chenu, C. (2010). Carbon dynamics in topsoil and in subsoil may be controlled by different regulatory mechanisms. Global Change Biology, 16, 416-426.

Schmidt, M. W. I., Torn, M. S., Abiven, S., Dittmar, T., Guggenberger, G., Janssens, I. A., ... Trumbore, S. E. (2011) Persistence of soil organic matter as an ecosystem property. Nature, 478, 49-56.

Schuerch, M., Spencer, T., Temmerman, S., Kirwan, M. L., Wolff, C., Lincke, D., ... Brown, S. (2018). Future response of global coastal wetlands to sea-level rise. Nature, 561, 231-234.

Schuur, E. A. G., Druffel, E. R. M., \& Trumbore, S. E. (Eds.). (2016). Radiocarbon and climate change (1st ed.). Switzerland: Springer International Publishing.

Shields, M. R., Bianchi, T. S., Mohrig, D., Hutchings, J. A., Kenney, W. F., Kolker, A., \& Curtis, J. H. (2017). Carbon storage in the Mississippi River delta enhanced by environmental engineering. Nature Geoscience, 10, 846-851.

Smith, R. W., Bianchi, T. S., Allison, M., Savage, C., \& Galy, V. (2015). High rates of organic carbon burial in fjord sediments globally. Nature Geoscience, 8, 450-453.

Sokol, N. W., \& Bradford, M. A. (2019). Microbial formation of stable soil carbon is more efficient from belowground than aboveground input. Nature Geoscience, 12, 46-53.

Spivak, A. C., Sanderman, J., Bowen, J. L., Canuel, E. A., \& Hopkinson, C. S. (2019). Global-change controls on soil-carbon accumulation and loss in coastal vegetated ecosystems. Nature Geoscience, 12, 685-692.

Stewart, C. E., Plante, A. F., Paustian, K., Conant, R. T., \& Six, J. (2008). Soil carbon saturation: Linking concept and measurable carbon pools. Soil Science Society of America Journal, 72, 379-392.

Syvitski, J. P., Kettner, A. J., Overeem, I., Hutton, E. W., Hannon, M. T., Brakenridge, G., ... Nicholls, R. J. (2009). Sinking deltas due to human activities. Nature Geoscience, 2, 681-686.

Trumbore, S. (2009). Radiocarbon and soil carbon dynamics. Annual Review of Earth and Planetary Sciences, 37, 47-66.

Van de Broek, M., Vandendriessche, C., Poppelmonde, D., Merckx, R., Temmerman, S., \& Govers, G. (2018). Long-term organic carbon sequestration in tidal marsh sediments is dominated by old-aged allochthonous inputs in a macrotidal estuary. Global Change Biology, 24, 2498-2512.

Wang, Y. Y., Wang, H., He, J. S., \& Feng, X. J. (2017). Iron-mediated soil carbon response to water-table decline in an alpine wetland. Nature Communications, 8, 15972.

Wei, X. R., Shao, M. G., Gale, W. J., \& Li, L. H. (2015). Global pattern of soil carbon losses due to the conversion of forests to agricultural land. Scientific Reports, 4, 4062-4062.
Wiesmeier, M., Urbanski, L., Hobley, E., Lang, B., Von Lutzow, M., Marinspiotta, E., ... Kögel-Knabner, I. (2019). Soil organic carbon storage as a key function of soils - a review of drivers and indicators at various scales. Geoderma, 333, 149-162.

Xu, J. M., \& Yuan, K. N. (1993). Dissolution and fractionation of calcium-bound and iron- and aluminum-bound humus in soils. Pedosphere, 3, 75-80.

Xue, C. T., Zhu, X. H., \& Lin, H. M. (1995). Holocene sedimentary sequence, foraminifera and ostracoda in west coastal lowland of Bohai Sea, China. Quaternary Science Reviews, 14, 521-530.

Xue, Y. J., Zou, L., Ge, T. T., \& Wang, X. C. (2017). Mobilization and export of millennial-aged organic carbon by the Yellow River. Limnology and Oceanography, 62, S95-S111.

Yin, S., Bai, J. H., Wang, W., Zhang, G. L., Jia, J., Cui, B. S., \& Liu, X. (2019). Effects of soil moisture on carbon mineralization in floodplain wetlands with different flooding frequencies. Journal of Hydrology, 574, 1074-1084.

Yu, J. B., Zhan, C., Li, Y. Z., Zhou, D., Fu, Y. Q., Chu, X. J., ... Wang, Q. (2016). Distribution of carbon, nitrogen and phosphorus in coastal wetland soil related land use in the Modern Yellow River Delta. Scientific Reports, 6, 37940.

Zhao, Q., Poulson, S. R., Obrist, D., Sumaila, S., Dynes, J. J., McBeth, J. M., \& Yang, Y. (2016). Iron-bound organic carbon in forest soils: Quantification and characterization. Biogeosciences, 13, 4777-4788.

Zhao, Q. Q., Bai, J. H., Zhang, G. L., Jia, J., Wang, W., \& Wang, X. (2018). Effects of water and salinity regulation measures on soil carbon sequestration in coastal wetlands of the Yellow River Delta. Geoderma, 319, 219-229.

Zhou, L. Y., Liu, J., Saito, Y., Gao, M. S., Diao, S. B., Qiu, J. D., \& Pei, S. (2016). Modern sediment characteristics and accumulation rates from the delta front to prodelta of the Yellow River (Huanghe). Geo-Marine Letters, 36, 247-258.

\section{SUPPORTING INFORMATION}

Additional supporting information may be found online in the Supporting Information section at the end of this article.

How to cite this article: $\mathrm{Li} \mathrm{Y,} \mathrm{Fu} \mathrm{C,} \mathrm{Zeng} \mathrm{L,} \mathrm{et} \mathrm{al.}$ Changes in organic carbon fractions and sources in deltaic topsoil and subsoil layers: autochthonous and allochthonous inputs. Eur J Soil Sci. 2021;1-16. https://doi.org/10.1111/ejss.13109 